\title{
Prevalence of syphilis and chlamydia in married females of Quetta
}

\author{
Bilqees Achakazai ${ }^{1}$, Ferhat Abbas ${ }^{1 *}$, Abdul Samad ${ }^{1}$, Hikmat Achakazai $^{2}$, \\ Akhtar Malghani², Hasil Khan Achakazai ${ }^{3}$, Wadan $\mathrm{Khan}^{3}$, Imran Taj $^{2}$, \\ Mohammad Zahid Mustafa ${ }^{2}$ and Muhammad Kamran Taj ${ }^{2}$ \\ 1. Center for Advanced Studies in Vaccinology \& Biotechnology (CASVAB), University of Balochistan, Quetta- \\ Pakistan \\ 2. Sandeman Provincial Civil Hospital, Quetta-Pakistan \\ 3. Bolan Medical College Hospital, Quetta-Pakistan \\ *Corresponding author's email: ferhatcasvab@yahoo.com \\ Citation \\ Bilqees Achakazai, Ferhat Abbas, Abdul Samad, Hikmat Achakazai, Akhtar Malghani, Hasil Khan Achakazai, \\ Wadan Khan, Imran Taj, Mohammad Zahid Mustafa and Muhammad Kamran Taj. Prevalence of syphilis and \\ chlamydia in married females of Quetta. Pure and Applied Biology. Vol. 6, Issue 3, pp1037-1043. \\ http://dx.doi.org/10.19045/bspab.2017.600110
}

\begin{tabular}{llll}
\hline \hline Received: 10/06/2017 & Revised: 17/08/2017 & Accepted: 28/30/2017 & Online First: 30/08/2017 \\
\hline
\end{tabular}

\section{Abstract}

The objective of the research was to study the prevalence of syphilis and chlamydia in married females who visited Gynecology OPD of Bolan Medical College Hospital Pakistan for different gynecological problems during the months of January to April 2016. Total number of female patients studied was 100. Out of which 86 were local females and 14 were immigrant/non-local immigrant female patients. Blood samples were collected and serum was separated for detection of antibodies against Syphilis and for the detection of chlamydia vaginal swabs were taken and tested using Immuno-chromatography Kits. Out of 100 females tested $2 \%$ were found positive for Syphilis and 15\% were found positive for chlamydia. Syphilis was detected in age group 28 to 37. Out of 15 chlamydia positive cases, 5 were detected in age group 18 to 27, 6 were detected in age group 28 to 37; one each was detected in age groups 38 to 47, 48 to 57, 58 to 67 and 68 to 77 respectively. Out of 86 local females tested, $12.79 \%$ were found positive for chlamydia and $2.32 \%$ were found positive for syphilis. Out of 14 non-local/immigrant females tested, $28.57 \%$ were positive for chlamydia and none was positive for syphilis. All females found positive either for syphilis or chlamydia were uneducated and had no knowledge of Sexually Transmitted Diseases (STD). Syphilis and chlamydia are important STDs which cause infertility and other health problems. Community based knowledge is important to prevent these diseases in married females of Quetta. A considerable \%age of females were found positive for syphilis and chlamydia in this study.

Keywords: Sexually; Transmitted; Diseases; Infertility; Gynecological

\section{Introduction}

Syphilis is caused by a gram negative bacterium, Spirochaete Treponema pallidum. It is responsible for diseases such as syphilis, bejel, pinta, and yaws.
Treponema palladium is grouped into four subspecies such as $T$. palladium, $T$. pendemicium, $T$. pcarateum, and $T$. ppertenue [1]. Sexual and vertical 
transmission of the disease has been reported [2].

Higher incidence of syphilis was noticed in 2010-2013 but later the use of antibiotics helped to reduce the incidence. In both developed and developing countries syphilis is a prevalent STD [3]. Asian regions are found more prevalent with this disease and it is also reported that Pakistan has the highest prevalence rate [4]. Syphilis can lead to problems in pregnant females such as decrease in birth weight, prematurity, and fetal death [5]. Syphilis becomes problematic in Pakistan because most of the time it does not show any symptoms [6].

Chlamydia is a bacterium but it resembles virus as it is unable to replicate outside a cell and it has both the RNA and DNA unlike a virus. It is not dependent like viruses and has its own enzymes. They are specifically adapted for extracellular survival [7]. C.psittaci is very prevalent in birds and in human infection occurs due the contracting the organism from dried droppings of infected birds. Chlamydiae trachomatis and Chlamydiae psittaci are the two important species. About 56 countries have reported trachoma as endemic [8]. It has been reported that 16-24 year age are more vulnerable to this disease [9]. Africa, the Middle East, South-East Asia, Northern India, South America and the Pacific regions are reported to suffering with this problem [10]. Genitourinary tract of the human beings is infected with $C$. trachomatis and the strains which are responsible for endemic trachoma initiate from the eye. Sometime the reproductive tract infection can lead to many serious problems [11].

As for as the diagnosis of syphilis and chlamydia is concerned, it can be diagnosed and detected by using many diagnostic tests. Syphilis can be very dangerous when it accompanies HIV. Seropositive cases have been reported in pregnant women $[12,13]$.
While C.trachomatis causes nongonococcal urethritis in man and cervicitis and pelvic inflammatory disease (PID) in women. Generalized infections can occur which can lead to pain, fever and arthritis. C.psittaci causes lung infections or an influenza-like disease. In a study conducted in Abbasi Shahid Hospital Karachi cervical samples were taken, $13.5 \%$ samples were positive by enzyme immunoassay while $5.6 \%$ samples were found positive by Giemsa-Staining method [14]. Nucleic acid amplification test (NAATs) is also a good technique to detect chlamydia infection but it's a little hard to standardize [15].

In this study we preferred to do antibody/antigen detection as this method is easy and quick. In addition antibodies can be detected from the blood for longer periods. Area wise Balochistan is the largest province but the population is less than other provinces. People do not have much awareness about these diseases in the province, on the other diagnostic facilities regarding the infection are scarce. If syphilis and chlymidia are diagnosed at proper time they can be treated. The aim of this work was rapid detection of antibodies/antigen against Treponema pallidum and chlamydia with the help of one-step rapid diagnostic kit in married females of Quetta which was achieved.

\section{Materials and methods}

Approval from the concerned ethical committee of Bolan Medical College and CASVAB, UOB was obtained before collection of the samples. Samples were collected from patients of Gynecology Department of Bolan Medical Collage Hospital, Quetta. For detection of syphilis, blood samples were taken from patients in sterilized blood collections tubes while for chlamydia, Cervical swabs were taken from patients by the trained hospital staff. Samples were brought to the bacteriology Lab of CASVAB, 
University of Balochistan Quetta and were analyzed on same day. For detection of Antibodies against syphilis blood samples were centrifuged at 6000 rmp for $3 \mathrm{~min}$ and serum was separated, Acon (Korea) Immunochromatograpic test kit/ Cassetts (ICT) were used. Using sterilized dropper provided with the kit, 2 to 3 drops were added to the kit well and waited for 15 minutes to read the results. For detection of chlamydia from cervical swab samples, 5 drops of reagent A (approximately 250 ul-colorless reagent) were added to the extraction tube. The swab was immediately inserted in the tube and six drops of reagent $B$ (approximately 300 ul-pale yellow) were added to the extraction tube. The swabs were rotated until the solution turned clear or slightly green or blue tint. The swab was squeezed against the side of tube and removed. Now six drops (approximately $300 \mathrm{ul}$ ) were taken and added to the cassette well of the chlamydia test kit and waited for 15 minutes to interpret the results. The results were interpreted according to the findings given below

Positive: Control and Test regions show red lines.

Negative: Only control shows red line.

Invalid: Control line does not appear

Results

Age wise prevalence

Syphilis and chlamydia both were found more prevalent in 28-37 year age group; in addition, it was also found that chlamydia was more prevalent as compared to syphilis in the females of Quetta as shown in Table 1 .

Table 1. Age wise distribution of chlamydia and syphilis in patients

\begin{tabular}{|l|c|c|}
\hline Age Group & Cases of chlamydia & Cases of syphilis \\
\hline $18-27$ & 05 & 0 \\
\hline $28-37$ & 06 & 02 \\
\hline $38-47$ & 01 & 0 \\
\hline $48-57$ & 01 & 0 \\
\hline $58-67$ & 01 & 0 \\
\hline $68-77$ & 01 & 0 \\
\hline Total & 15 & 02 \\
\hline
\end{tabular}

Community wise prevalence

Local people of Quetta showed higher infected number of syphilis while chlamydia was found more prevalent in immigrants as shown in Table 2.

Table 2. Location wise frequency of syphilis and chlamydia cases

\begin{tabular}{|c|c|c|}
\hline Cases & Locals (n=86) & Immigrants (n=14) \\
\hline Chlamydia & $11(12.79 \%)$ & $04(28.57 \%)$ \\
\hline Syphilis & $02(2.32 \%)$ & $0(0 \%)$ \\
\hline
\end{tabular}

\section{Socioeconomic wise prevalence}

It was seen in the study that illiterate patients were more infected with syphilis and chlamydia than literate. While in case of socioeconomic status syphilis and chlamydia infections were seen to be more frequent in lower middle class and lower class, as shown in Table 3.

According to the history taken from the patients, most the patients were found with the complaint of previous illness and infertility. Watery discharge from the nose 
was observed in only one syphilis positive case out of hundred while vaginal discharge was observed in $30 \%$ cases of chlamydia positive cases as shown in Table 4.

Table 3. Socioeconomic wise prevalence of syphilis and chlamydia cases

\begin{tabular}{|l|l|l|l|l|l|l|}
\hline ID & Education & Purpose of visit & Previous illness & Syphilis & Chlamydia & $\begin{array}{l}\text { Husband } \\
\text { job }\end{array}$ \\
\hline 04 & $\begin{array}{l}\text { Only islamic } \\
\text { study }\end{array}$ & PID infertility & $\begin{array}{l}\text { TB } \\
\text { appendisectomy }\end{array}$ &. & + & $\begin{array}{l}\text { Shop } \\
\text { keeper }\end{array}$ \\
\hline 09 & Nil & PID infertility & Stomach pain &. & + & Business \\
\hline 11 & Nil & Dys-menorrhea & Lower back pain & + &. & Farmer \\
\hline 17 & Nil & PID infertility & &. & + & Driver \\
\hline 18 & Primary & PID infertility & Low back pain &. & + & NGO \\
\hline 23 & Nil & PID infertility & &. & + & Driver \\
\hline 37 & Nil & PID infertility & Uterine cyst &. & + & Driver \\
\hline 38 & Islamic & PID infertility & TB &. & + & Driver \\
\hline 48 & Nil & PID infertility & $\begin{array}{l}\text { Low back pain } \\
\text { irregular periods }\end{array}$ &. & + & Driver \\
\hline 52 & Nil & PID infertility & Diabetes &. & + & Driver \\
\hline 54 & Nil & PID infertility & Dysmenorrhea &. & + & Driver \\
\hline 61 & Primary & PID infertility & Typhoid &. & + & Driver \\
\hline 73 & Nil & PID infertility & Apendisectomy &. & + & Driver \\
\hline 82 & Nil & PID infertility & & + weak &. & Driver \\
\hline 84 & Primary & PID infertility & Stomach pain, &. & + & Driver \\
\hline 89 & Nil & PID infertility & Hepatitis-B &. & + & Driver \\
\hline 98 & Nil & PID infertility & Hepatitis-B &. & + & Driver \\
\hline
\end{tabular}

Table 4. Frequency of watery discharge from nose and vaginal discharge in patients with and without PIDs

\begin{tabular}{|l|c|c|}
\hline Frequency of watery discharge \\
\hline No of sample & Detected & Undetected \\
\hline 100 & $1 / 100$ & $99 / 100$ \\
\hline Syphilis (PIDs) & $1 \%$ & $99 \%$ \\
\hline \multicolumn{2}{|c|}{ Frequency of vaginal discharge } \\
\hline No of swab sample & Detected & Undetected \\
\hline 100 & $30 / 100$ & $70 / 100$ \\
\hline Chlamydia (PIDs) $100 \%$ & $30 \%$ & $70 \%$ \\
\hline
\end{tabular}

\section{Discussion}

Among the health problems in developing countries sexually transmitted disease are the major ones. Despite increase efforts in health education and encouragement of safer sex practices, the incidence of PID continues to rise. The symptoms such as watery discharge from nose, painful vaginal inflammation, appearance of rashes on the body, reduced red blood cells (anemia) hepato and splenomegali, and enlargement of lymph nodes are indicative of the infection. Screening of the disease can help to prevent the problem; 
developed countries like Russia and China are working on health preventive programs. The problem is very much existing in the developing countries. Infected pregnant females face abortions and stillbirths and $20 \%$ perinatal deaths have also been reported by some workers [16]. A strong relationship of syphilis has been observed with sexual behavior as it has been found more in men having sex with men [17]. Syphilis symptoms have become less severe in $19^{\text {th }}$ and $20^{\text {th }}$ century because of the use of effective antibiotics [18]. In china rate of syphilis has decreased from the 1990s to the 2010s. This occurred after a successful campaign in the 1950s [19].

In 2000-2005, 0.3-0.6\% syphilis was found in women while it was observed 7$15 \%$ in drug users. Between 1980 and 2000 the rate of syphilis reduced due to the use of antibiotics, similar results were also reported from West Bengal where prevalence of syphilis was found reduced from $10.8 \%$ to $3.6 \%$ between 2004 and 2008 [20].

A global incidence of $0.15 \%$ of Syphilis has been estimated by WHO in 2012 in both sexes. WHO also estimates 5.6 million new cases of the disease in 2012 [21].

As for as chlamydia is concerned, worldwide the chlamydia is reported more at the age of 15-19 year and 2024 year [22]. It becomes very problematic in cases where reproductive tract infections get severe. In the international studies, we found strong relationship between the prevalence of male concurrency and syphilis/chlamydia prevalence [23]. Some researchers suggest no correlation between knowledge, age or socioeconomic status and according to them chlamydia risk increases from 15 years of age till 19 years which could be because of changing sexual partners [24] but in our study maximum cases of chlamydia were observed between 28-37 year of age. Same researchers have reported that in $\mathrm{UK}$, in
2012, 3000,300 diagnosis of early infectious syphilis were recorded, of which $91 \%$ were in men and highest rates of infections were observed in 15-24 year of age. In our study we found it in 2837 year of age. The disease is very common throughout the world including many Asian countries.

Different tests including nucleic acid amplification test are in use for chlamydia but we preferred antibody/antigen detection as it does not require much skills and is easier and less expensive.

This study was conducted in Balochistan, Pakistan. In Balochistan, the chlamydia was found more prevalent in 28-37 year age group. Syphilis was also recorded more in 28-37 year age group. The reason could be that these age groups are productive age groups and could be more prone to infection. The other thing observed was people did not have any education or know how about STDs.

\section{Conclusion}

Syphilis and chlamydia are important STDs which cause infertility and other health problems. Community based knowledge are important to prevent STDs in married females of Quetta. A considerable \%age of females were found positive for syphilis and chlamydia. The age group between 28-37 year was found more prone to infection.

Chlamydia was observed with a higher \%age (28.57) in immigrants as compared to locals (12.79) while syphilis was observed higher in locals $(2.32 \%)$ as it was not observed in immigrants at all.

\section{Authors' contributions}

Conceived and designed the experiments: $\mathrm{F}$ Abbas, A Samad \& I Taj, Performed the Experiments: B Achakazai, A Samad \& MK Taj, Analyzed the Data: M Z Khan, Contributed reagents/ materials/ analysis tools: H Achakazai, A Malghani, H Khan \& W Khan, Wrote the paper: B Achakazai. 


\section{Acknowledgements}

Authors are grateful and would like to thank colleagues and lab attendants of CASVAB, University of Balochistan for collecting the samples and data for making the research possible in a successful manner.

\section{References}

1. Antal GM, Lukehart SA \& Meheus AZ (2002). The endemic treponematoses. Microbes Infect 4(1): 83-94.

2. Kent ME \& Romanelli F (2008). Reexamining syphilis: an update on epidemiology, clinical manifestations, and management. Annals Pharma 42(2): 226-236.

3. Allain JP, Stramer SL, Carneiro-Proietti A, Martins M \& Lopes SS (2009). Transfusion-transmitted infectious diseases. Biol 37(2): 71-77.

4. Karla S, Tuli A, Goyal U, Choudhary R \& Raheja S (2002). Correlation of anticardiolipin antibody IgM with first trimester recurrent abortions. J Anat Soc India 51(1): 10-13.

5. Khan A, Tayyib M, Tasneem, Farooq M, Rehman F \& Ujjan I (2004). Serum anticardiolipin antibodies in recurrent abortion. Ann King Edward Med Coll 10(4): 406-407.

6. Rahman M, Akhtar GN \& Yasmin L (2002). Seroprevalence of syphilis in the blood donors in Lahore. Pak J Med Sci 18: 284-286.

7. Alison JC \& Kenneth WB (2010). Chlamydia trachomatis, a Hidden Epidemic: Effects on female Reproduction and option for Treatment. Am J Reprod Immunol 63(6): 576-586.

8. Polack S, Brooker S, Kuper H, Mariotti S \& Mabey D (2005). Mapping the global distribution of trachoma. Bull World Heal Organ 83: 913-919.

9. Lin CC, Gao X, Chen XS, Chen Q \& Cohen MS (2006). Chinas syphilis epidemic: a systematic review of seroprevalence studies. Se Trans Dise 33(12): 726-736.

10. Frick KD, Hanson CL \& Jacobson GA (2003). Global burden of trachoma and economics of the disease. Am J Trop Med 1(69): 1-10.

11. Evans TG \& Ranson MK (1995). The global burden of trachomatous visual impairment: II. Assessing burden. Int Ophthalmol 2(19): 271-280.

12. Peterman TA, Heffelfinger JD, Swint EB \& Groseclose SL (2005). The changing epidemiology of Syphilis. Sex Transm Dis 32(3): S4-10.

13. Woods CR (2009). Congenital syphilispersisting pestilence. Pediat Infect Dis $J$ 28(6): 536-537.

14. Asrul AW, Rahman MM \& Salasawati H (2013). Case series of syphilis and HIV co-infections. Pak J Med Sci 29(3): 856-858.

15. Cook RL, Hutchison SL, Stergaard L, Braithwaite RS \& Ness RB (2005). Systematic review: noninvasive testing for Chlamydia trachomatis and Neisseria gonorrhea. Ann Intern Med 42(11): 914925.

16. Stamm LV (2010). Global challenge of antibiotics-resistant Treponema pallidum. Antimicrob Agents Chemother 54 (2): 583-589.

17. Van-Dommelen L, Van-Tiel FH \& Ouburg S (2010). Alarmingly poor performance in Chlamydia trachomatis point-of-care testing. Sex Transm Infect 86(5): 355-359.

18. Mullooly C \& Higgins SP (2010). Secondary syphilis :the classical triad of skin rash, mucosal ulceration and lymphadenopathy. Inter J STD and AIDS 21(8): 537-545.

19. Tucker JD \& Cohen MS (2011). Chinas syphilis epidemic: epidemiology proximate determinants of spread, and control responses. Curr Opi Infec Dise 24(1): 50-55. 
20. Maity S, Bhunia S, Biswas S \& Saha M (2008). Syphilis seroprevalence among patients attending a sexually transmitted disease clinic in west Bengal, India. J Infect Dis 64(4): 506508.

21. Newman L, Rowley J, Vander HS, Wijesooriya NS, Unemo M \& Low N (2015). Global estimates of the prevalence and incidence of four curable sexually transmitted infections in 2012 based on systematic review and global reporting. PLOS 10(12): $143304 \quad$ 143310 .
22. Schmid G (2004). Economic and programmatic aspects of congenital syphilis prevention. Bull WHO 82(1): 402-409.

23. Chris RK \& Karla O (2015). The prevalence of syphilis is associated with the prevalence of male pointconcurrency. An Ecol Analys 2(5): 131139.

24. Gwenda H \& Nigel F (2015). The epidemiology of sexually transmitted infections in the UK: impact of behavior, services and interventions. Future Microbiol 10(1): 35-51. 